\title{
Correction to: Role of Silent Information Regulator 1 (SIRT1) in Regulating Oxidative Stress and Inflammation
}

\author{
Saba Ubaid, ${ }^{1}$ Mohammad Rumman, ${ }^{1}$ Babita Singh, ${ }^{1}$ and Shivani Pandey ${ }^{1,2}$
}

Correction to: Inflammation (2020) 43(5):1589-1598

https://doi.org/10.1007/s10753-020-01242-9

Following publication of our original article, we noticed that Mohammad Rumman, Babita Singh, and Shivani Pandey had been inadvertently omitted as co-authors. The author list is now complete and no changes are required to the Conflict of Interest statement.

The online version of the original article can be found at https://doi.org/ 10.1007/s10753-020-01242-9

\footnotetext{
${ }^{1}$ King George's Medical University (KGMU), Lucknow, U.P 226003, India

${ }^{2}$ To whom correspondence should be addressed at King George's Medical University (KGMU), Lucknow, U.P 226003, India. E-mail: dr.shivani111263@gmail.com
} 